\title{
Economic Efficiency of Alcohol Policy
}

\author{
Christopher M. Doran and Thameemul A. Jainullabudeen
}

National Drug and Alcohol Research Centre, University of New South Wales, Sydney, New South Wales, Australia

The production, sale and use of alcohol has proliferated since the first recordings of alcohol use in the middle ages. ${ }^{[1]}$ Today, alcohol is consumed by over 2 billion people, with global sales of alcoholic beverages in excess of \$US967 billion (year 2005 value).${ }^{[2,3]}$ Alcohol has many positive features, including individual pleasure to the drinker; a lubricant in the context of socializing and celebration; aesthetic appreciation; a source of income, employment and export; a promoter of other economic activities; and a generator of tax revenue ${ }^{[4]}$ Conversely, alcohol consumption and, in particular, excessive or harmful use of alcohol can bring about many negative consequences, including adverse health effects, reduced productivity and/or increased workforce absenteeism, crime and violence, road traffic accidents and premature death. ${ }^{[2,4-6]}$

Recent advances have been made in understanding the health implications of alcohol misuse, with the weight of the evidence suggesting that the misuse of alcohol represents a leading cause of illness, injury and premature mortality. ${ }^{[4,7,8]}$ Epidemiologists have ascertained causal relationships between average volume of alcohol consumed and more than 60 types of disease and injury. ${ }^{[4]}$ An estimated $3.8 \%$ of deaths and $4.6 \%$ of disability-adjusted life-years are attributable to alcohol use globally. ${ }^{[4]}$ However, the burden across countries is not equally distributed. Disease burden is closely related to average volume of alcohol consumption, and, for every unit of exposure, is strongest in people who are poor and marginalized in society. ${ }^{[4]}$ Economic costs associated with alcohol misuse indicate that more than $1 \%$ of GDP purchasing power parity in high- and middle-income countries is attributable to alcohol consumption. ${ }^{[4,9-12]}$

The evidence base underpinning the negative consequences of alcohol misuse for drinkers, their families and society, while sometimes lacking in rigorous scientific quality, ${ }^{[13]}$ supports the claim that using alcohol inappropriately is harmful to one's health and a considerable drain of society's scarce resources. Given that this evidence base is derived predominantly from developed countries, the call for alcohol action is more heeded in developed countries than developing countries. However, in a review of alcohol action in 12 developed countries, Crombie et al. ${ }^{[14]}$ found that countries varied markedly in their commitment to intervene, with very little consensus on which strategies to adopt or what levels of drinking should be targeted.

To date, the development of alcohol policy has largely been ad hoc and reactive, with subsequent policy relying on strategies that are ineffective but popular. ${ }^{[13,15]}$ For example, school-based education is an ineffective measure to reduce alcoholrelated harm but is nonetheless a very popular option with governments and their constituencies. ${ }^{[15]}$ Conversely, volumetric taxation is a very costeffective strategy to curb alcohol misuse but is rarely adopted. ${ }^{[16]}$ While countries such as Australia and the UK have at least attempted to curb alcoholrelated harm through a range of measures, too many countries are still lagging behind the development of effective and appropriate alcohol policy. A range of factors impede such a process, including political instability or a vested interest in governments in alcohol manufacturing, a lack of appreciation of the evidence base, challenges 
imposed by free trade agreements and involvement of the alcohol industry in policy processes. ${ }^{[17]}$ Although there is some consolidated evidence, such as the WHO European Action Plan, ${ }^{[18]}$ put together to guide policy makers on what constitutes an essential package of interventions to reduce alcohol-related harm, there is still a lack of international guidance.

The call for effective and appropriate alcohol policy to address alcohol-related harm has recently gained momentum. ${ }^{[13,16,17,19]}$ A comprehensive global assessment by the $\mathrm{WHO}^{[15]}$ of the effectiveness of policies and programmes to reduce alcohol-related harm found that policies that regulated the environment in which alcohol is marketed (particularly its price and availability) are effective in reducing alcohol-related harm, as is legislation to reduce drink-driving and brief interventions targeted at risky drinkers. ${ }^{[15]}$

An under-researched area in the development of effective and efficient alcohol policy is the role of economics and, in particular, the need for economically efficient strategies. Economic efficiency can be improved in the alcohol market when the negative externalities due to alcohol consumption can be reduced and where the socially optimum level of alcohol is sold and consumed in society. A socially optimum level can be one where the level of harm is minimized. This optimum level requires an assessment of both supply-side factors (availability, marketing and price of alcohol) and demand-side factors (taste, willingness, preferences and income) and the interactions of these factors in minimizing alcohol misuse.

Although the evidence base pertaining to economic efficiency of alcohol policy is sparse, there have been some valuable contributions. Her et al. ${ }^{[20]}$ found that greater availability of alcohol through privatizing of alcohol sales in a retail environment where the government is also a retailer can increase alcohol harm. Chaloupka et al. ${ }^{[21]}$ reviewed the economic literature pertaining to price elasticity and found that price increases can reduce the quantity of alcohol consumed and alcohol-related harm. Cook and Moore ${ }^{[22]}$ highlighted the importance of price increases and restricting access in reducing use and harm. Doran and Shakeshaft ${ }^{[23]}$ recommended combining fiscal measures of volumetric taxation with other supply- and demand-side initiatives to provide incentives to manufacturers to extend the product development of low-strength beer and wine and disincentives aimed at reducing the manufacture of high alcohol-content drinks and marketing of alcohol to young and vulnerable subgroups of the population. Cobiac et al. ${ }^{[16]}$ suggested that the Australian Government, by implementing a package of cost-effective interventions, could bring about a 10-fold improvement in health gains compared with current practise.

One of the most economically efficient measures to reduce alcohol-related harm is taxation. ${ }^{[15]}$ There are two economic rationales for taxation of alcohol: to correct market failures, specifically the externality costs associated with alcohol consumption; and to raise taxation revenue for governments. ${ }^{[2]}$ These two rationales suggest varying approaches to the application of taxation on alcoholic beverages. The former suggests a taxation regime that aims to internalize the external costs within the market by applying a marginal tax directly to the cost driver of the externality, equal to the marginal cost of the externality, thereby realigning marginal private costs with the marginal social costs associated with consuming alcohol. In this sense, alcohol taxation can be described as a Pigovian tax, attempting to align private consumption levels with the socially optimal level of consumption. Alternatively, the latter of the two rationales proposes a taxation rate inversely proportional to alcohol products' price elasticities in order to maximize taxation revenue.

From a social perspective, tax policy that corrects market failure is more attractive than a tax that simply aims to raise government revenue. The body of evidence that shows alcohol consumption is responsive to retail price increases is consistent within the range of pricing policies. ${ }^{[15,21,22]}$ This increase in retail price can be achieved by various forms of taxes, the common one being excise taxes. It is proposed that a volumetric tax, which taxes alcohol equally across beverage types, is less distortive of consumer preferences and more efficient at reducing alcohol 
consumption than current taxation models seen in most developed countries, i.e. where taxes are charged at varying amounts per litre of pure alcohol, depending on the beverage type.

Byrnes et al. ${ }^{[25]}$ examined the public health benefits and costs of implementing a volumetric alcohol tax in Australia. A mathematical model was created to compare three scenarios for a volumetric tax rate: (i) a rate that maintains the current deadweight loss of taxation (i.e. the reduction in consumer benefit from taxation that increases the price and lowers consumption, less the taxation revenue collected); (ii) a rate that maintains existing taxation revenue; and (iii) a rate equal to the existing rate applied to spirits (the highest taxed beverage in Australia). The results suggest that all volumetric tax scenarios would provide greater health benefits and cost savings to the health sector than the existing taxation system. The findings of Byrnes et al. ${ }^{[25]}$ are supported by other researchers ${ }^{[21,23]}$ and reinforce the potential role that economics can play in the design of effective and efficient alcohol policy.

\section{Where to From Here?}

Applied Health Economics and Health Policy invites the submission of original manuscripts on the health economic implications of various alcohol policies, to be published in a special issue in 2011. Manuscripts may be either methodological or applied pieces that range from assessments of the efficiency of current global alcohol policy to demonstrations of how economics may improve the situation. The deadline for submissions is 31 March 2011 (see the Call for Papers at the back of this issue).

\section{Acknowledgements}

No sources of funding were used to prepare this editorial. The authors have no conflicts of interest that are directly relevant to the content of this editorial.

\section{References}

1. Hanson DJ. Preventing alcohol abuse: alcohol, culture and control. Westport: Praeger, 1995
2. WHO. Global status report on alcohol 2004. Geneva: WHO, 2004

3. Euromonitor International. Strategy briefings: global drinking habits. July 2006 [online]. Available from URL: http:// www.euromonitor.com/Global_Drinking_Habits [Accessed 2010 Jul 15]

4. Rehm J, Mathers C, Popova S, et al. Global burden of disease and injury and economic cost attributable to alcohol use and alcohol-use disorders. Lancet 2009 Jun 27; 373 (9682): 2223-33

5. Mangione TW, Howland J, Amick B, et al. Employee drinking practices and work performance. J Stud Alcohol 1999; 60 (2): 261-70

6. Roche AM, Pidd K, Berry JG, et al. Workers' drinking patterns: the impact on absenteeism in the Australian work-place. Addiction 2008; 103 (5): 738-48

7. Rehm J, Room R, Graham K, et al. The relationship of average volume of alcohol consumption and patterns of drinking to burden of disease: an overview. Addiction 2003; 98: 1209-28

8. Rehm J, Room R, Monteiro M, et al. Alcohol use. In: Ezzati M, Lopez AD, Rodgers A, et al., editors. Comparative quantification of health risks: global and regional burden of disease attributable to selected major risk factors. Vol. 1. Geneva: WHO, 2004: 959-1109

9. Thavorncharoensap M, Teerawattananon Y, Lertpitakpong C, et al. The economic costs of alcohol consumption in Thailand. Nonthaburi: Health Intervention and Technology Assessment Program, Ministry of Public Health, 2008

10. Collins DJ, Lapsley HM. Counting the cost: estimates of the social costs of drug abuse in Australia in 1998-1999. Canberra (ACT): Publication Production Unit, Commonwealth Department of Health and Ageing, 2002

11. Johansson P, Jarl J, Eriksson A, et al. The social costs of alcohol in Sweden 2002. Stockholm: Stockholm Social Research on Alcohol and Drugs, 2006 [online]. Available from URL: http://www.drugslibrary.stir.ac.uk/documents/ soradcosts.pdf [Accessed $2010 \mathrm{Jul}$ 20]

12. Delvin NJ, Scuffham PA, Bunt LJ. The social costs of alcohol abuse in New Zealand. Addiction 1997; 92: 1491-505

13. Doran CM, Hall WD, Shakeshaft AP, et al. Alcohol policy reform in Australia: what can we learn from the evidence? Med J Australia 2010 April 19; 192 (8): 468-70

14. Crombie IK, Irvine L, Elliott L, et al. How do public health policies tackle alcohol-related harm: a review of 12 developed countries. Alcohol Alcohol 2007; 42 (5): 492-9

15. Anderson P, Chisholm D, Fuhr DC. Effectiveness and costeffectiveness of policies and programmes to reduce the harm caused by alcohol. Lancet 2009; 373 (9682): 2234-46

16. Cobiac L, Vos T, Doran C, et al. Cost-effectiveness of interventions to prevent alcohol-related disease and injury in Australia. Addiction 2009; 104: 1646-55

17. Casswell S, Thamarangsi T. Reducing harm from alcohol: call to action. Lancet 2009; 373: 2247-57

18. WHO. Handbook for action to reduce alcohol-related harm. Copenhagen: WHO Regional Office for Europe, 2009 [online]. Available from URL: http://www.euro.who.int/ data/assets/pdf_file/0012/43320/E92820.pdf [Accessed 2010 Aug 5]

19. Anderson P. Global alcohol policy and the alcohol industry. Curr Opin Psychiatry 2009 May; 22 (3): 253-7 
20. Her M, Giesbrecht N, Room R, et al. Privatizing alcohol sales and alcohol consumption: evidence and implications. Addiction 1999; 94: 1125-39

21. Chaloupka FJ, Grossman M, Saffer H. The effects of price on alcohol consumption and alcohol-related problems. Alcohol Res Health 2002; 26 (1): 22-34

22. Cook PJ, Moore MJ. The economics of alcohol abuse and alcohol-control policies. Health Aff 2002; 21 (2): 120-33

23. Doran CM, Shakeshaft AP. Using taxes to curb drinking in Australia. Lancet 2008; 372: 701-2

24. Parry IWH, Laxminarayan R, West SE. Fiscal and externality rationales for alcohol taxes [discussion paper 06-51]. Washington, DC: Resources for the Future, 2009 [online].
Available from URL: http://www.rff.org/rff/Documents/ RFF-DP-06-51-REV.pdf [Accessed 2010 Jul 15]

25. Byrnes JM, Cobiac LJ, Doran CM, et al. Cost-effectiveness of volumetric alcohol taxation in Australia. Med J Australia 2010; 192 (8): 439-44

Correspondence: Associate Professor Christopher M. Doran, Health Economist, National Drug and Alcohol Research Centre, University of New South Wales, Sydney, NSW 2052, Australia.

E-mail: c.doran@unsw.edu.au 